\title{
A new multi-product closed-loop supply chain network design in dairy industry
}

\begin{abstract}
Masoud. Alinezhad ${ }^{1, *}$
Nowadays, manufacturers need to satisfy consumer demands in order to compete in the real world. This requires the efficient operation of supply chain planning. On the other hand, increasing worldwide environmental, lack of food resources and social concerns are motivating manufacturers and consumers to implement recycling strategies such as product recovery, waste management, or usage of recycled materials. In this study, the closed-loop supply chain network has been proposed which consists of four echelons (suppliers, plants, distribution centers, and customers) in the forward chain and three echelons (collection centers, inspection centers, and disposal centers) in the backward chain. We present a multi-product and multi-period mixedinteger linear programming problem in this paper. The objective of this study is to maximize the profit in the closed-loop supply chain network. The proposed model is applied to an illustrative example based on inspiration from the dairy industry in Iran. The solution of the proposed model is achieved by using Gams software. The results give important insight for fostering the decision making process.
\end{abstract}

Keywords: Close-loop supply chain, mixed-integer linear programming, Network design, Dairy industry.

Manuscript was received on 21/01/2019, revised on 01/07/2019 and accepted for publication on 20/08/2019.

\section{1.introduction}

Recently, food industry has endured an enormous change. Resources become rare, ecosystems are threatened, and the subsequences of climate variation have a major impact on the living environment, and in recent years, people have begun to pay attention to environmental and social responsibilities and the economic benefits of used products, which make people attach importance to reverse supply chain network (Meade et al. [22]). In addition, the recent frauds and swindles that have occurred on food safety laws have attracted the attention of consumers and forced politicians to respond to the food supply chain and their tracking and monitoring systems. In today's competitive market, every product should have two factors in order to succeed. Firstly, it should entice customer satisfaction, and secondly, its cost must be reasonable. Factors include the quality of the supplier's performance, the quality of the raw materials, the service way of distributers of the product, the performance of retailers, and many other external factors affect these two characteristics.

supply chain is one of the most significant issues in other to increase customer satisfaction and decrease cost of whole chain. A supply chain is referred to as a combined system which synchronizes a series of related processes in order to: (1) buy raw material and parts, (2) convert these raw materials and parts into end products and (3) distribute these products to either retailers or customers (Selim and Ozkarahan [32]). However, nowadays, an increasing flow of returned products from customers

\footnotetext{
${ }^{1}$ Department of Industrial Engineering, Mazandaran University of Science and Technology, Babol, Iran, m.alinezhad.ie@gmail.com .
} 
to the manufacturer is happening for a whole range of enterprises due to government regulations and the environmental consciousness of customers (Qin and Ji [30]). In general, in the forward logistic, as a conventional logistic, after purchasing from suppliers, raw materials are converted to finished products in manufacturing plants, and then these products are transferred to customers via distribution centers to satisfy their demands (Baumgarten et al. [6] and Schultmann et al. [29]).

In the last decade, due to global warming in particular, growing attention has been paid to reverse logistics, which refers to activities that are dedicated to the collection, repair, recovery, recycling and/or disposal of the returned products within supply chain management. Many companies, such as Kodak and Xerox, have concentrated on remanufacturing and recycling activities and achieved important successes in this area (Üster et al. [39]). When a forward and reverse logistics network is considered simultaneously, a closed-loop supply chain network will be established.

In this study we present a multi-product, multi-period closed-loop supply chain network design model in which the demand and the return rate are certain. The structure of the closed-loop network includes three echelons in the forward direction (i.e. echelons constituted by the flow among the entities of suppliers, plants, distribution centers and customers) and three echelons in the backward direction (i.e. echelons constituted by the flow arcs among the entities of customers, collection centers, inspection centers and disposal centers). The rest of the paper is organized as follows. In the next section we review the related literature. The concerned problem is defined in Section 3 and the proposed mixed-integer linear programming model for closed-loop supply chain network design is presented in Section 4. Numerical analysis is reported in Section 5 and finally, concluding remarks and some possible future works are given in Section 6.

\section{Literature Review}

In this section, the researches on the supply chain, reverse supply chain, closed-loop supply chain, and then the food supply chain will be reviewed.

\subsection{Supply chain}

Melo et al. [23] presented a general review of supply chain network design models to support the development of richer supply chain network design models. They also mention that traditional supply chain network design methods typically focus on deterministic and single-objective approach in forward logistics. Chan and Chung [8] showed a chain network design in the forward logistic, with the objective of minimization of costs, total delivery days and the equity of the capacity utilization rate for manufacturers. They proposed a multi-objective genetic approach for the order distribution problem in a demand logistic network. Sun et al. [33] presented a multi-objective programming model for location of logistic distribution centers by considering benefits of customers and logistics planning departments.

\subsection{Reverse supply chain}

Fleischmann et al. [13] presented a comprehensive review on the application of mathematical modeling in reverse logistics management. As one of the seminal works in reverse supply chain network design, Barros et al. [5] proposed a mixed-integer linear programming model for a sand recycling network. A heuristic algorithm is also used to solve the problem. Jayaraman et al. [16] developed a mixed-integer linear programming model for reverse logistics network design under a pull system based on customer demands for recovered products. The objective of the proposed model was to minimize the total costs. Also, Krikke et al. [19] designed a mixed-integer linear programming model for a two-stage reverse supply chain network for a copier manufacturer. In this model, both 
the processing costs of returned products and inventory costs were included in the objective function to minimize the total cost.

Jayaraman et al. [17] extended their prior work to solve the single product two-level hierarchical location problem involving the reverse supply chain operations of hazardous products. They also developed a heuristic to handle relatively large sized problems. Min et al. [21] proposed a mixedinteger nonlinear programming model and a genetic algorithm that could solve a multi-period reverse logistics network design problem involving both spatial and temporal consolidation of returned products. Aras et al. [1] developed a mixed-integer nonlinear programming model for determining the locations of collection centers in a simple reverse supply chain network. The important point about this work was the capability of presented model in determining the optimal buying price of used products with the objective of maximizing profit. They developed a heuristic approach based on Tabu search to solve the model. Pati et al. [27] proposed a mixed-integer goal programming model for paper recycling logistics network design. The considered goals include: (1) minimizing the positive deviation from the planned budget allocated for reverse logistics activities, (2) minimizing the positive deviation from the maximum limit of non-relevant wastepaper and (3) minimizing the negative deviation from the minimum desired waste collection.

\subsection{Closed-loop supply chain}

The concept of closed-loop supply chain is now widely garnering attention as a result of the recognition that both the forward and reverse supply chains need to be managed jointly. The configuration of both forward and reverse supply chain networks has a strong influence on the performance of each other. Therefore, to avoid the sub-optimality resulting from the separated design, the design of the forward and reverse networks should be integrated (Pishvaee et al. [28] and Fleischmann et al. [14]). Subramanian et al. [35] presented a single-period, single-product and multiechelon closed-loop supply chain and develop a multi-objective integer linear programming using simulated annealing algorithms. Soleimani et al. [34] investigated a multi-echelon, multi-product, and multi-period mixed-integer linear programming model. The model is solved by CPLEX optimization software and a developed GA. Subramanian et al. [36] proposed a multi-period, multi-product closedloop supply chain network design with the goal of minimizing the costs and maximize the efficiency. Their model is a two-objective mixed integer linear programming model; Operational/Location decisions for distributors and production and distribution between each stage.

Amin et al. [4] proposed a multi-product closed loop supply chain network which focused on a tire remanufacturing system. They also optimized multiple products, suppliers, plants, retailers, demand markets, and drop-off depots in the model. The goal of the model is to maximize the total profit. Kaya and Urek [20] designed a closed-loop supply chain that integrates the collection of the used products with the distribution of the new products. The objective model is maximizing the total supply chain profit. They also developed a heuristic for the proposed multi-echelon model. Sahebjamnia et al. [37] proposed a multi-objective mixed integer linear programming model for designing of tire closed-loop supply chain network. Paydar et al. [29] proposed a bi-objective model for closed-loop supply chain of used engine oil. Their model maximizing profit and minimizing the risk of closed-loop supply chain under different scenarios.

Jabbarzadeh et al. [18] proposed a Closed-loop Supply Chain Network Design under Disruption Risks. The objective model is to minimize the total supply chain cost (including fixed costs of establishing facilities, transportation costs, inventory costs and lost sales costs) under each disruption scenario. They also develop a Lagrangian relaxation algorithm in order to solve the developed model efficiently. Cardoso et al. [11] formulated a mixed-integer linear programming model that integrates financial risk measures in a closed loop supply chain. The goal is maximizing expected net present 
value, while simultaneously minimizing the associated risk in the network. They also used $\varepsilon^{-}$ constraint to solve the model.

Chen et al. [9] presented a multi-objective, multi-stage closed-loop supply chain design. for this study, two objectives including minimization of total cost and carbon emission reduction were used for the network. They used a deterministic mixed integer linear programming as the methodology. Özceylan et al. [26] presented a multi-period, multi-product, and multi-level linear programming definitive model for a closed-loop supply chain in the automotive industry. They applied a deterministic linear programming to address their model. Wei et al. [41] presented a closed-loop supply chain with symmetric and asymmetric information structures. They also used game theory in their study. Dutta et al. [12] suggested a recovery framework for a multi-period closed loop supply chain with the goal of improving rate of returned goods by using the buy-back offer. Al-Salem et al. [3] formulated a mixed integer non-linear program model to minimize the total cost related to forward and reverse logistic networks. They used the piecewise method to linearize the non-linear objective function. According to their findings, significant cost saving can be achieved because of integration of the forward and reverse flows which leads to a closed loop supply chain. Gholizadeh et al. [15] presented a multilayered closed-loop supply chain. The objective of the model is to maximize the value of reverse products and direct supply products. Vahdani and Mohammadi [40] proposed a multiobjective model for a closed-loop supply chain with the goal of minimizing total costs and waiting time in the queue.

\subsection{Food supply chain}

In this section we reviewed some study about food industry in all supply chains. Amorim et al. [2] present a multi-objective model to minimize the costs, and maximize the remaining shelf life of a perishable product. Teimoury et al. [38] presented a perishable fruits and vegetables supply chain. They proposed a simulation model using system dynamics approach in order to study the behaviors and relationships within the supply chain and to specify the impact of the supply, demand and price interactions. Banasik et al [7] presented the consequences of closing loop supply chain in a mushroom industry. They proposed a multi-objective mixed integer linear programming model to quantify tradeoffs between economic and environmental indicators and explore quantitatively alternative recycling technologies. Meneghetti and Monti [24] proposed a sustainable food supply chain that investigate the effect of supply chain decision variables, storage temperature and the incoming-product temperature on costs, energy use and carbon dioxide emissions. Mohammed et al. [25] presented a multi-objective programming model with the aim of minimizing the total cost of transportation and implementation, the amount of $\mathrm{CO} 2$ emissions in transportation, and the time of products distribution from farms to slaughterhouses and from slaughterhouses to retailers and maximizing the average delivery rate in satisfying product quantity as requested by slaughterhouses and retailers.

\section{Model definition}

In this section, we suggested a multi-product and multi-period closed loop supply chain network including supplier, manufacturing center, distribution, customer zone, collecting, inspection, and disposal centers with deterministic demand and return rate product. The model includes four layers in the forward flow (supplier, manufacturing centers, distribution centers, and customers) and three layers in the backward flow (collection centers, inspection centers, and disposal centers). The process of producing the product is as follows: the suppliers are accountable for providing raw material to manufacturing centers based on their orders in each period. After produce the products, they are shipped to the distributor. It is significant to be noted that the products are sent immediately because of the short expiration date of some dairy products. At the distribution center, if the product has the 
standard expiration date, it will be accepted and sent to the customer, otherwise it will be returned. In the backward flow, the returned product from customers and outdate product from distributers are collected and shipped to collection centers. After collecting and sending products to the inspection center, the quality control test is done on them. The returned products are divided into two recoverable and disposal group after quality inspection. The recoverable products are shipped to manufacturing centers, and disposal ones are sent to disposal centers. The general structure of the proposed closed loop supply chain network design is illustrated in Figure 1.
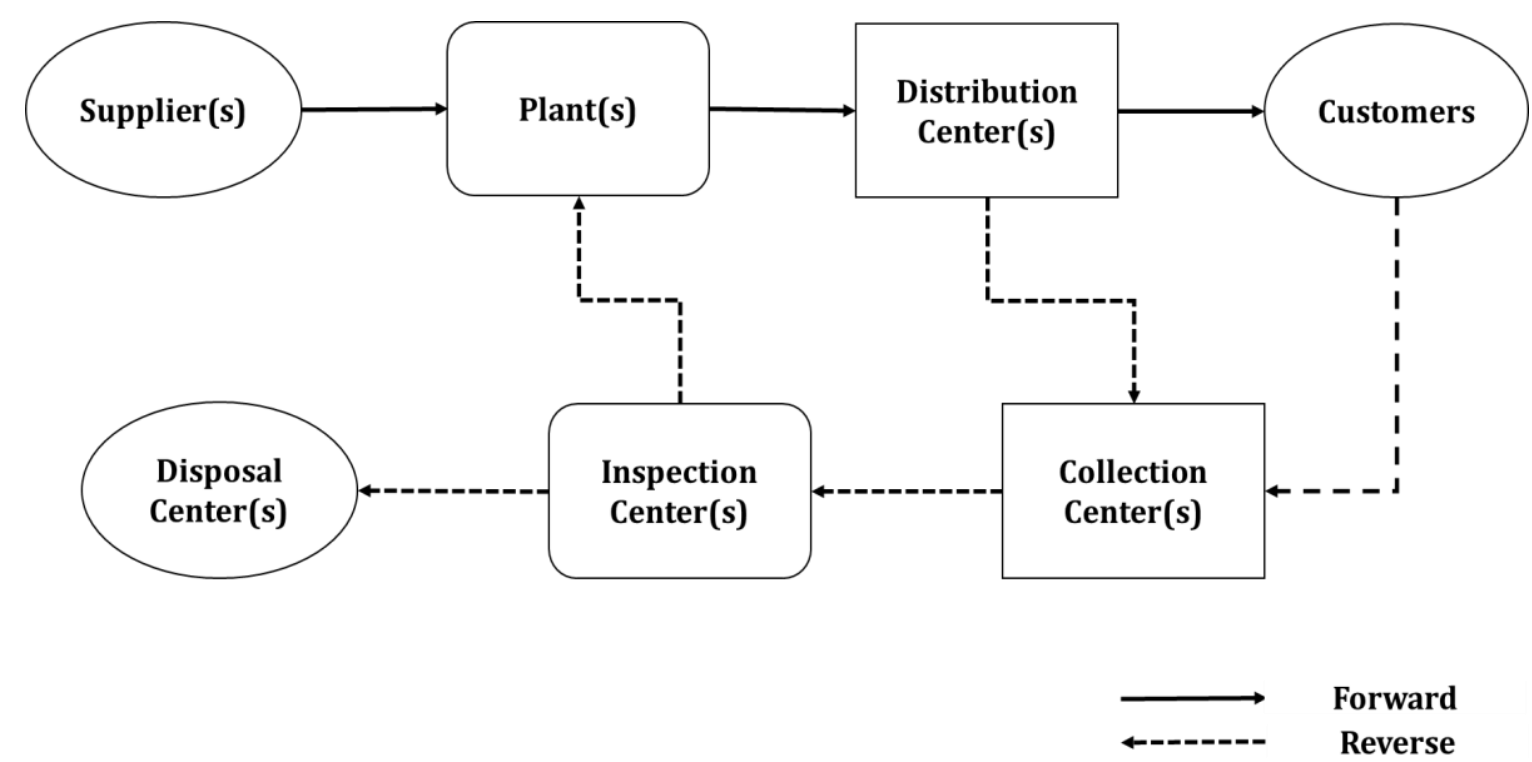

Figure. 1 Structure of the closed loop supply chain regarded in this research.

\subsection{Assumptions}

- The Closed-loop supply chain design model is multi-product and multi-period.

- The inventory holding cost is considered for supplier centers.

- Demand backlog is not allowed.

- The position of all sections is fixed.

- the transfer cost between production center and inspection center is neglected.

- The demand backlog and the initial inventory are considered zero in the first period.

- Products are received in distribution section, if they have standard time to distribute, otherwise they are sent to collection centers.

\subsection{Model formulation}

Definitions of sets, parameters and variables used in the model formulation are described below:

The set of indices

$\begin{array}{lll}S & \text { Index for suppliers } & s=1 \ldots S \\ r & \text { Index for raw materials } & r=1 \ldots R\end{array}$




$\begin{array}{lll}i & \text { Index for manufacturing plants } & i=1 \ldots I \\ j & \text { Index for products } & j=1 \ldots J \\ d & \text { Index for distributors } & d=1 \ldots D \\ c & \text { Index for customer centers } & c=1 \ldots C \\ m & \text { Index for collection centers } & m=1 \ldots M \\ n & \text { Index for inspection centers } & n=1 \ldots N \\ l & \text { Index for disposal center } & l=1 \ldots L \\ t & \text { Index for period } & t=1 \ldots T\end{array}$

Parameters

$D E_{j t} \quad$ Demand of product $j$ in period $t$

$P R_{j t} \quad$ Unit price of product $j$ in period $t$

$S C_{r s t} \quad$ Buying cost of one unit of raw material $r$ from provider $s$ in period $t$

$S C a p_{\text {srt }} \quad$ Capacity of provider $s$ for raw material $r$ in period $t$

$T C S_{r s i t} \quad$ Unit production cost of product $r$ from supplier $s$ at factory $i$ in period $t$

$p c_{j i t} \quad$ Unit production cost of product $j$ at factory $i$ in period $t$

$R P_{j i t} \quad$ Unit remanufacturing cost of product $j$ at factory $i$ in period $t$

Pcap $_{j i t} \quad$ Capacity of product $j$ at factory $i$ in period $t$

$T C p_{j i d t} \quad$ Unit transportation cost of product $j$ shipped from factory $i$ to distribution center $d$ in period $t$

$H C_{\text {rit }} \quad$ Holding cost of raw material $r$ at factory $i$ in period $t$

$\operatorname{Dcap}_{j d t} \quad$ Capacity of product $j$ at distribution center $d$ in period $t$

$T C D_{j d c t} \quad$ Unit transportation cost of product $j$ shipped from distribution center $d$ to client $c$ in period $t$

$T C C_{j c m t} \quad$ Unit transportation cost of returned product $j$ shipped from client $c$ to collection center $m$ in period $t$ 
$\operatorname{Ccap}_{j m t} \quad$ Capacity of product $j$ at collection center $m$ in period $t$

$T C M_{\text {jmnt }}$ Unit transportation cost of product $j$ sent from collection center $m$ to inspection center $n$ in period $t$

$\operatorname{Insc}_{j n t} \quad$ Unit inspection cost of product $j$ at inspection center $n$ in period $t$

Cins $_{j n t} \quad$ Capacity of product $j$ at inspection center $n$ in period $t$

$\operatorname{Disc}_{j l t} \quad$ Unit disposal cost of product $j$ at disposal center $l$ in period $t$

Cdis $s_{j l t} \quad$ Capacity of product $j$ at disposal center $l$ in period $t$

TCdis jnlt Unit transportation cost of product $j$ shipped from inspection center $n$ to disposal center $l$ in period $t$

$\mu_{r j} \quad$ Amount of raw material $r$ needed to produce product $j$ in period $t$

$r_{j c t} \quad$ Return ratio of product $j$ in period $t$

$\varphi_{j t} \quad$ The possibility of product $j$ that is reusable after inspection in period $t$

$M \quad$ A big number

Decision variables

$Q R M_{\text {rsit }} \quad$ Quantity of raw materials $\mathrm{r}$ shipped from supplier s to plant $\mathrm{i}$ in period $\mathrm{t}$

$Q P D_{j i d t} \quad$ Quantity of product $\mathrm{j}$ shipped from plant $\mathrm{i}$ to distribution center $\mathrm{d}$ in period $\mathrm{t}$

$Q D C_{j d c t} \quad$ Quantity of product $\mathrm{j}$ shipped from distribution center $\mathrm{d}$ to customer $\mathrm{c}$ in period $\mathrm{t}$

$Q D C C_{j d m t}$ Quantity of returned product $\mathrm{j}$ shipped from distribution center $\mathrm{d}$ to collection center $\mathrm{m}$ in period $\mathrm{t}$

$Q C C_{j c m t} \quad$ Quantity of returned product $\mathrm{j}$ shipped from customer $\mathrm{c}$ to collection center $\mathrm{m}$ in period $\mathrm{t}$

$Q C I_{\text {jmnt }} \quad$ Quantity of returned product $\mathrm{j}$ shipped from collection center $\mathrm{m}$ to inspection center $\mathrm{n}$ in period $\mathrm{t}$

$A_{\text {jnit }} \quad$ Quantity of returned product $\mathrm{j}$ that they are reusable at inspection center $\mathrm{n}$ in period $\mathrm{t}$

$Q I D_{\text {jnlt }} \quad$ Quantity of product $\mathrm{j}$ shipped from inspection center $\mathrm{n}$ to disposal center $\mathrm{l}$ in period $\mathrm{t}$

$I_{\text {rit }} \quad$ Raw material inventory $r$ at plant $i$ in period $t$ 
$y_{j d t} \quad\{1$ if the product $j$ is accepted in distributor $d$ in period $t$ 0 otherwise

Objective function

$$
\begin{aligned}
\operatorname{Max} Z= & \sum_{j=1}^{J} \sum_{d=1}^{D} \sum_{c=1}^{C} \sum_{t=1}^{T} Q D C_{j d c t} P R_{j t}-\sum_{r=1}^{R} \sum_{s=1}^{S} \sum_{i=1}^{I} \sum_{t=1}^{T} Q R M_{r s i t} S C_{r s t} \\
& -\sum_{j=1}^{J} \sum_{i=1}^{I} \sum_{d=1}^{D} \sum_{t=1}^{T} P C_{j i t} Q P D_{j i d t}-\sum_{j=1}^{J} \sum_{n=1}^{N} \sum_{i=1}^{I} \sum_{t=1}^{T} A_{j n i t} R P_{j i t} \\
& -\sum_{r=1}^{R} \sum_{i=1}^{I} \sum_{t=1}^{T} I_{r i t} H C_{r i t}-\sum_{j=1}^{J} \sum_{m=1}^{M} \sum_{n=1}^{N} \sum_{t=1}^{T} Q C I_{j m n t} I_{n s C_{j n t}} \\
& -\sum_{r=1}^{r} \sum_{s=1}^{S} \sum_{i=1}^{I} \sum_{t=1}^{T} Q R M_{r s i t} T C S_{r s i t}-\sum_{j=1}^{J} \sum_{i=1}^{I} \sum_{d=1}^{D} \sum_{t=1}^{T} Q P D_{j i d t} T C p_{j i d t} \\
& -\sum_{j=1}^{J} \sum_{d=1}^{D} \sum_{c=1}^{C} \sum_{t=1}^{T} Q D C_{j d c t} T C D_{j d c t}-\sum_{j=1}^{J} \sum_{c=1}^{C} \sum_{m=1}^{M} \sum_{t=1}^{T} Q C C_{j c m t} T C C_{j c m t} \\
& -\sum_{j=1}^{J} \sum_{m=1}^{M} \sum_{n=1}^{N} \sum_{t=1}^{T} Q C I_{j m n t} T C M_{j m n t}-\sum_{j=1}^{J} \sum_{n=1}^{N} \sum_{l=1}^{L} \sum_{t=1}^{T} Q I D_{j n l t} T C d i s
\end{aligned}
$$

The constraints comprised in the present closed loop supply chain design in the dairy industry are expressed by equations. (2) -(17).

$$
\begin{array}{lc}
I_{\text {rit }}=I_{\text {rit }-1}+\sum_{s=1}^{S} Q R M_{r s i t}+\sum_{j=1}^{J} A_{j n i t}-\sum_{j=1}^{J} \mu_{r j} \sum_{d=1}^{D} Q P D_{j i d t} & \forall r . i . t \\
\sum_{i=1}^{I} Q P D_{j i d t}=\sum_{c=1}^{C} Q D C_{j d c t}+\sum_{m=1}^{M} Q D C C_{j d m t} & \forall d . j . t \\
\sum_{c=1}^{C} Q D C_{j d c t} \leq M y_{j d t} & \forall d . j . t \\
\sum_{m=1}^{M} Q D C C_{j d m t} \leq M\left(1-y_{j d t}\right) & \forall d . j . t \\
\sum_{m=1}^{M} Q C C_{j c m t}=r_{j c t} \sum_{d=1}^{D} Q D C_{j d c t} & \forall j . c . t \\
\sum_{d=1}^{D} Q D C C_{j d m t}+\sum_{c=1}^{C} Q C C_{j c m t}=\sum_{n=1}^{N} Q C I_{j m n t} & \forall m . j . t \\
\sum_{m=1}^{M} Q C I_{j m n t}=\sum_{i=1}^{I} A_{j n i t}+\sum_{l=1}^{L} Q I D_{j n l t} & \forall n . j . t \\
\sum_{i=1}^{I} A_{j n i t}=\sum_{m=1}^{M} Q C I_{j m n t} \varphi_{j t} & \forall n . j . t \\
\sum_{d=1}^{D} \sum_{c=1}^{C} Q D C_{j d c t} \geq D E_{j t} & \forall j . t
\end{array}
$$




$$
\begin{array}{lc}
\sum_{i=1}^{I} Q R M_{r s i t} \leq \operatorname{SCap}_{r s t} & \forall \text { s.r.t } \\
\sum_{d=1}^{D} Q P D_{j i d t}+I_{j d t-1} \leq \operatorname{Pcap}_{j i t} & \forall i . j . t>1 \\
\sum_{c=1}^{C} Q D C_{j d c t} \leq D c a p_{d j t} & \forall d . j . t \\
\sum_{d=1}^{D} Q D C C_{j d m t}+\sum_{c=1}^{C} Q C C_{j c m t} \leq C c a p_{j m t} & \forall m . j . t \\
\sum_{m=1}^{M} Q C I_{j m n t} \leq C i n s_{j n t} & \forall n . j . t \\
\sum_{n=1}^{N} Q I D_{j n l t} \leq C d i s_{j l t} & \forall \text { l.j.t } \\
Q R M_{r s i t}, Q P D_{j i d t}, Q D C_{j d c t}, & \\
Q D C C_{j d m t}, Q C C_{j c m t}, Q C I_{j m n t}, & \\
A_{j n t}, Q I D_{j n l t}, Q_{j t}, I_{j d t}, Q D B_{j t} \geq 0 &
\end{array}
$$

The objective function (1) is aimed to maximize the profit in the dairy closed loop supply chain. This objective derives from the subtraction of selling products from the costs of the chain. The total costs of the closed loop supply chain are calculated by the sum of the supplier cost, production cost, distribution cost, collection cost, inspection cost, disposal cost and transportation costs between the centers. Constraint (2) displays inventory level balance for any kind of raw material. Constraint (3) shows that the amount of product delivered to the distributor is equal to the amount of product sent to the customers plus the amount of product sent to the collection center. Constraints (4) and (5) guarantee that only one of the variables $Q D C_{j d c t}$ and $Q D C C_{j d m t}$ will be set. In fact, these two limitations indicate that in case of the acceptance of each product at each distributor, it is sent to the customer. Otherwise, it is sent to the collection center. Constraint (6) shows the amount of returned products from each customer $\mathrm{C}$ in each period. Constraint (7) states that the amount of products come to inspection center from the distributor and collection center. Constraint (8) is connected to the flow of the inspection center and indicates that the amount of product delivered from the collection center to the inspection center is greater than or equal to the amount of reusable product plus the amount of product sent to the disposal center. Constraint (9) states that the amount of reusable product can be used as other raw material. Constraint (10) ensures that demands for each product must be fully met. Constraint (11) - (16) shows capacity constraint in each supplier, manufacturer, distributer, collection, inspection, and disposal centers. Constraint (17) guarantees that the related decision variables are non-negative.

\section{Case explanation}

The Kalleh brand was established with the aim of improving and upgrading the food basket of the Iranian people in 1991. The Kalleh brand produces the dairy products like all kinds of milk and its 
supplements like cheese, butter, dough and yogurt. The Kalleh has 16 production groups and has a large volume of Iran dairy market. The Kalleh Dairy Company transforms 2500 tons of raw milk to over 160 types of dairy products every day. The Kalleh has 12 subsidiary companies. The size of the Kalleh Dairy Factory is 15 acres and it is one of the largest factories in the whole industry of Iran. Now, the Kalleh distributes its products from the north to the south using distribution channel and more than 44 branches. The Kalleh is profitable in terms of product dimensions, not in the volume of supply. The strength of the Kalleh brand in the market is due to the true recognition of the people taste, creating a variety of products and entering new products into the market. Currently, there are three business units of cheese, pasteurized and Ultra heat treated (UHT) products in the Kalleh company. Each of these units produces the highest quality and most diversified products by its innovation and supplies them in the high production volume to the market.

\section{Illustrative example}

In this section a numerical example is presented to illustrate how the proposed model works in a multi-product, multi-period closed loop supply chain framework. A data set is prepared reflecting the small scale of the real business situation. It is supposed that there are two types of suppliers, two types of raw materials, one type of manufacture, two types of products, two types of distributors, four types of customers, two types of collecting centers, one type of inspecting center, and one type of disposal center. Customers' demands and the return rate products are intended to be equal to 1000 and 0.05 respectively. The production costs of the supply chain network are shown in Table 1. Table 2 presents the amounts of the transportation cost between each node. Table 3 presents the maximum capacity of each center.

Table 1. Production costs

\begin{tabular}{cc}
\hline Parameters & Values \\
\hline$R_{j t}$ & uniform $(5000,10000)$ \\
$S C_{r s t}$ & uniform $(500,1000)$ \\
$p c_{j i t}$ & uniform $(1000,1500)$ \\
$R P_{j i t}$ & uniform $(100,150)$ \\
$H C_{j d t}$ & uniform $(100,200)$ \\
$I n s c_{j n t}$ & uniform $(70,100)$ \\
$D i s c_{j l t}$ & uniform $(70,100)$ \\
$\varphi_{j t}$ & uniform $(0.85,0.9)$
\end{tabular}


$\mu_{r j} \quad$ uniform $(0,2)$

Table 2. Transportation cost between each node

\begin{tabular}{cc}
\hline Parameters & Values \\
\hline$T C S_{\text {rsit }}$ & uniform $(10,20)$ \\
$T C p_{\text {jidt }}$ & uniform $(20,25)$ \\
$T C D_{j d c t}$ & uniform $(12,19)$ \\
$T C C_{j c m t}$ & uniform $(12,19)$ \\
$T C M_{j m n t}$ & uniform $(10,15)$ \\
$T C$ dis $_{\text {jnlt }}$ & uniform $(13,18)$
\end{tabular}

Table 3. Holding capacity in each node

\begin{tabular}{cc}
\hline Parameters & Values \\
\hline SCap $_{\text {srt }}$ & uniform $(10000,11000)$ \\
Pcap $_{j i t}$ & uniform $(8000,10000)$ \\
ccap $_{j d t}$ & uniform $(9000,12000)$ \\
Ccap $_{j m t}$ & uniform $(4500,5000)$ \\
Cins $_{j n t}$ & uniform $(4500,5000)$ \\
Cdis $_{j l t}$ & uniform $(4500,5000)$
\end{tabular}

To analyze the performance of the proposed model, the model is coded and solved using GAMS 25.0 optimization software. The amount of objective function is 58118116. Every section of objective function is presented in Table 4.

Table 4. The values of each objective function

Objective value Cost




\begin{tabular}{lc}
\hline Material purchasing cost & 4076926 \\
Production cost & 1615160 \\
Remanufacturing cost & 80255 \\
Holding cost & 411291 \\
Inspection cost & 10377 \\
Transportation cost & 1347163 \\
\hline
\end{tabular}

Table 5 and Figure 2shows the behavior of the objective function with increasing in the supplier capacity. As illustrated in Figure 2, the increase in capacity has positive relationship with the increase in objective function. Creating extra providers and outsourcing of manufacturing the products can be alternatives to solve this problem.

Table 5. Increasing in supplier capacity center

\begin{tabular}{|c|c|c|c|c|c|c|c|c|c|c|c|}
\hline $\begin{array}{c}\text { Increase } \\
\text { in }\end{array}$ & 0 & 10 & 20 & 30 & 40 & 50 & 60 & 70 & 80 & 90 & 100 \\
capacity \\
$(\%)$
\end{tabular}




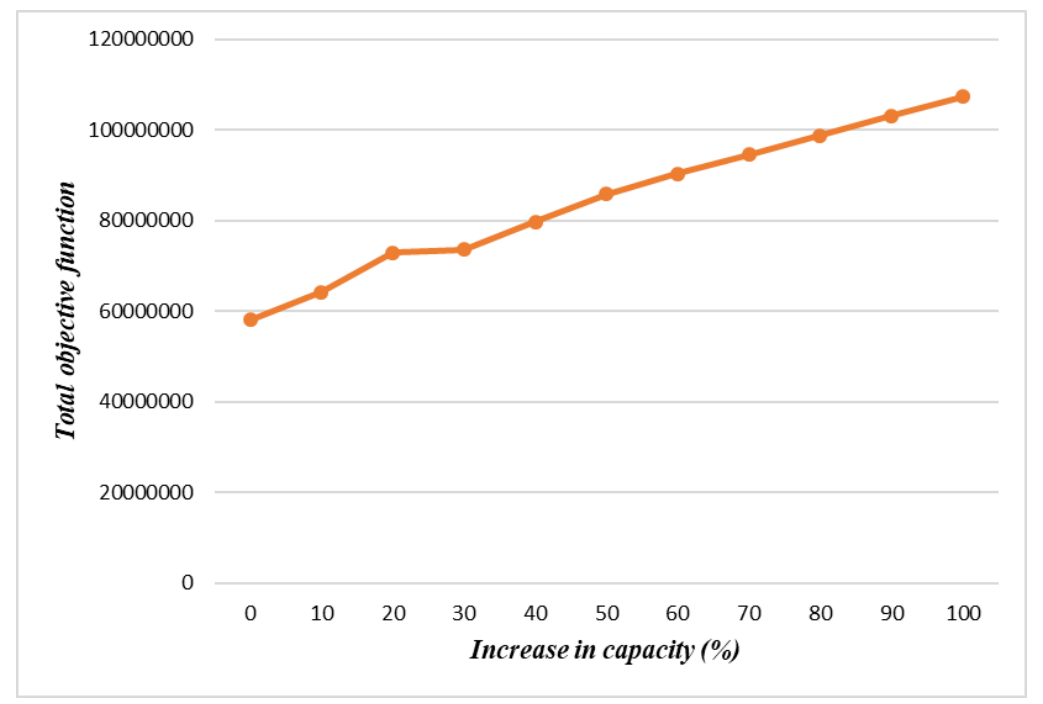

Figure 2. The behavior of the objective function in different capacity

Table 6 shows increase in the products return rate. As observed in this table along with figure 3a, Figure $3 b$ and Figure $3 c$, the cost of purchasing the raw materials is decreased with the increase in the product return rate and subsequently increase in the objective function. However, the costs of the productions maximize again with a higher slope. In other words, the augmentation of the return rate is not a profitable solution for increasing the profits because the rate of rework and frequent manufacturing in the operation section increases as well.

Table 6. Impact of rising Return rate of product on the model

\begin{tabular}{cccc}
\hline $\begin{array}{c}\text { Return rate of } \\
\text { product }\end{array}$ & $\begin{array}{c}\text { Raw material } \\
\text { purchasing coat }\end{array}$ & $\begin{array}{c}\text { Remanufacturing } \\
\text { costs }\end{array}$ & $\begin{array}{c}\text { Total objective } \\
\text { function }\end{array}$ \\
\hline 0.05 & 40769260 & 80255 & 58118116 \\
0.1 & 40499780 & 162927 & 59854666 \\
0.15 & 40221840 & 248123 & 61644212 \\
0.2 & 39935040 & 335962 & 63489238 \\
0.25 & 39638950 & 426566 & 65392384 \\
0.3 & 39333110 & 520069 & 67356465 \\
\hline
\end{tabular}




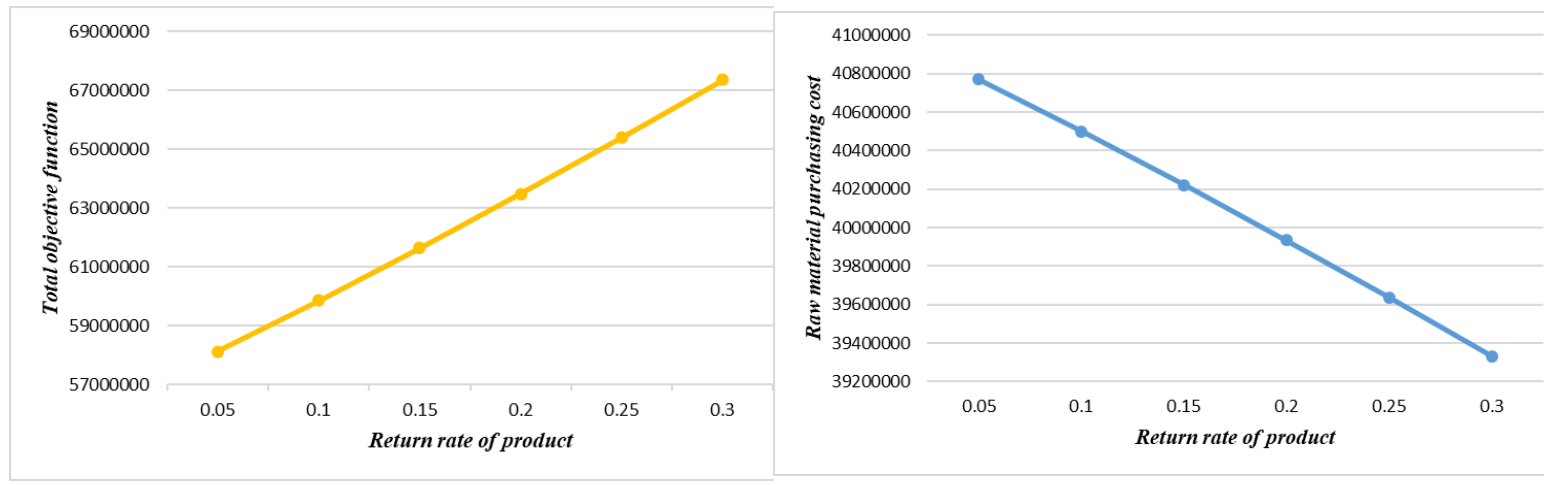

Figure 3a. The behavior of the objective Figure 3b. The behavior of raw cost in different function in different return rate of product return rate of product

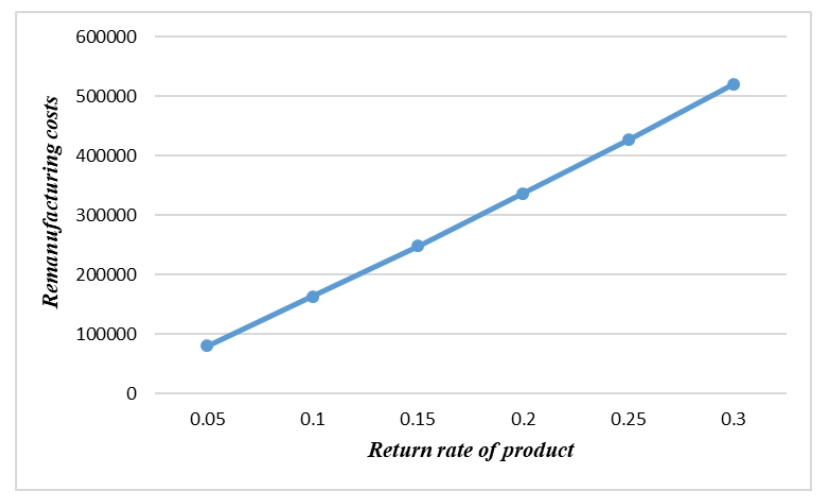

Figure 3c. The behavior of remanufacturing cost in different return rate of product

\section{Conclusion}

In this research, a deterministic model is proposed for multi-period, multi-product a closed loop supply chain. The model includes four layers in the forward flow (suppliers, manufacturing centers, distribution centers, and customer zone) and three layers in the reverse flow (collection center, inspection center, and disposal centers). The model objective is to maximize the chain profit with considering economic characteristics. The model is devised according to the current situation of the factory under study. Also the factory's constraints such as methods of accepting the products in the distribution center for delivering the products to customers are regarded in this model. In order to validate and show the model mathematical application, numerical examples are performed by CPLEX. The conclusions show that we can increase the objective functions by increasing the capacities. It also shows that a change in the return rate can lead to both augmentations in the chain profit and reduction in the costs of purchasing the raw materials. In this research, several opportunities are considered for future research: 1. developing exact methods or using customized meta-heuristic algorithm for the large size problems due to their high computational time, 2) considering uncertainty in the model parameters especially in the demand and return rate of product, and 3) taking into account 
more objective functions in the model. For example, environmental and customer satisfaction objectives such as minimization of demand backlog can be added to the model.

\section{Reference}

[1] Aras, N., Aksen, D., \& Tanuğur, A. G. (2008). Locating collection centers for incentivedependent returns under a pick-up policy with capacitated vehicles. European Journal of Operational Research, 191(3), 1223-1240.

[2] Amorim, P., Günther, H. O., \& Almada-Lobo, B. (2012). Multi-objective integrated production and distribution planning of perishable products. International Journal of Production Economics, 138(1), 89-101.

[3] Al-Salem, M., Diabat, A., Dalalah, D., \& Alrefaei, M. (2016). A closed-loop supply chain management problem: Reformulation and piecewise linearization. Journal of Manufacturing Systems, 40, 1-8.

[4] Amin, S. H., Zhang, G., \& Akhtar, P. (2017). Effects of uncertainty on a tire closed-loop supply chain network. Expert Systems with Applications, 73, 82-91.

[5] Barros, A. I., Dekker, R., \& Scholten, V. (1998). A two-level network for recycling sand: a case study. European journal of operational research, 110(2), 199-214.

[6] Baumgarten, H., Butz, C., Fritsch, A., \& Sommer-Dittrich, T. (2003, May). Supply chain management and reverse logistics-integration of reverse logistics processes into supply chain management approaches. In IEEE International Symposium on Electronics and the Environment, 2003. (pp. 79-83). IEEE.

[7] Banasik, A., Kanellopoulos, A., Claassen, G. D. H., Bloemhof-Ruwaard, J. M., \& van der Vorst, J. G. (2017). Closing loops in agricultural supply chains using multi-objective optimization: A case study of an industrial mushroom supply chain. International Journal of Production Economics, 183, 409-420.

[8] Chan, F. T., \& Chung, S. H. (2004). A multi-criterion genetic algorithm for order distribution in a demand driven supply chain. International Journal of Computer Integrated Manufacturing, 17(4), 339-351.

[9] Chen, Y. W., Wang, L. C., Wang, A., \& Chen, T. L. (2017). A particle swarm approach for optimizing a multi-stage closed loop supply chain for the solar cell industry. Robotics and Computer-Integrated Manufacturing, 43, 111-123.

[10] Yeh, W.C. (2002a), Search for all $d$-Mincuts of a limited-flow network, Computers and Operations Research, 29(13), 1843-1858.

[11] Cardoso, S. R., Barbosa-Povoa, A. P., \& Relvas, S. (2016). Integrating financial risk measures into the design and planning of closed-loop supply chains. Computers \& Chemical Engineering, 85, 105-123.

[12] Dutta, P., Das, D., Schultmann, F., \& Fröhling, M. (2016). Design and planning of a closedloop supply chain with three-way recovery and buy-back offer. Journal of Cleaner Production, 135, 604-619.

[13] Fleischmann, M., Bloemhof-Ruwaard, J. M., Dekker, R., Van der Laan, E., Van Nunen, J. A., \& Van Wassenhove, L. N. (1997). Quantitative models for reverse logistics: A review. European journal of operational research, 103(1), 1-17.

[14] Fleischmann, M., Beullens, P., BLOEMHOF- RUWAARD, J. M., \& Van Wassenhove, L. N. (2001). The impact of product recovery on logistics network design. Production and operations management, 10(2), 156-173.

[15] Gholizadeh, H., Tajdin, A., \& Javadian, N. (2018). A closed-loop supply chain robust optimization for disposable appliances. Neural Computing and Applications, 1-19. 
[16] Jayaraman, V., Guide Jr, V. D. R., \& Srivastava, R. (1999). A closed-loop logistics model for remanufacturing. Journal of the operational research society, 50(5), 497-508.

[17] Jayaraman, V., Patterson, R. A., \& Rolland, E. (2003). The design of reverse distribution networks: models and solution procedures. European journal of operational research, 150(1), 128-149.

[18] Jabbarzadeh, A., Haughton, M., \& Khosrojerdi, A. (2018). Closed-loop supply chain network design under disruption risks: A robust approach with real world application. Computers \& Industrial Engineering, 116, 178-191.

[19] Krikke, H. R., van Harten, A., \& Schuur, P. C. (1999). Business case Oce: reverse logistic network re-design for copiers. Or-Spektrum, 21(3), 381-409.

[20] Kaya, O., \& Urek, B. (2016). A mixed integer nonlinear programming model and heuristic solutions for location, inventory and pricing decisions in a closed loop supply chain. Computers \& Operations Research, 65 , 93-103 .

[21] Min, H., Ko, C. S., \& Ko, H. J. (2006). The spatial and temporal consolidation of returned products in a closed-loop supply chain network. Computers \& Industrial Engineering, 51(2), 309-320.

[22] Meade, L., Sarkis, J., \& Presley, A. (2007). The theory and practice of reverse logistics. International Journal of Logistics Systems and Management, 3(1), 56-84.

[23] Melo, M. T., Nickel, S., \& Saldanha-Da-Gama, F. (2009). Facility location and supply chain management-A review. European journal of operational research, 196(2), 401-412.

[24] Meneghetti, A., \& Monti, L. (2015). Greening the food supply chain: an optimisation model for sustainable design of refrigerated automated warehouses. International Journal of Production Research, 53(21), 6567-6587.

[25] Mohammed, F., Selim, S. Z., Hassan, A., \& Syed, M. N. (2017). Multi-period planning of closed-loop supply chain with carbon policies under uncertainty. Transportation Research Part D: Transport and Environment, 51, 146-172.

[26] Özceylan, E., Demirel, N., Çetinkaya, C., \& Demirel, E. (2017). A closed-loop supply chain network design for automotive industry in Turkey. Computers \& Industrial Engineering in press.

[27] Pati, R. K., Vrat, P., \& Kumar, P. (2008). A goal programming model for paper recycling system. Omega, 36(3), 405-417.

[28] Pishvaee, M. S., Farahani, R. Z., \& Dullaert, W. (2010). A memetic algorithm for biobjective integrated forward/reverse logistics network design. Computers \& operations research, 37(6), 1100-1112.

[29] Paydar, M. M., Babaveisi, V., \& Safaei, A. S., (2017). An engine oil closed-loop supply chain design considering collection risk, Computers \& Chemical Engineering, 104, 38-55.

[30] Qin, Z., \& Ji, X. (2010). Logistics network design for product recovery in fuzzy environment. European journal of operational research, 202(2), 479-490.

[31] Schultmann, F., Zumkeller, M., \& Rentz, O. (2006). Modeling reverse logistic tasks within closed-loop supply chains: An example from the automotive industry. European journal of operational research, 171(3), 1033-1050.

[32] Selim, H., \& Ozkarahan, I. (2006, November). Application of fuzzy multi-objective programming approach to supply chain distribution network design problem. In Mexican International Conference on Artificial Intelligence (pp. 415-425). Springer, Berlin, Heidelberg.

[33] Sun, H., Gao, Z., \& Wu, J. (2008). A bi-level programming model and solution algorithm for the location of logistics distribution centers. Applied mathematical modelling, 32(4), 610-616.

[34] Soleimani H., Seyyed-Esfahani M., Akbarpour Shirazi M., (2013). Designing and planning a multi-echelon multi-period multi-product closed-loop supply chain utilizing genetic 
algorithm. The International Journal of Advanced Manufacturing Technology. Volume 68. P 917-931.

[35] Subramanian P., Ramkumar N., Narendran T.T., Ganesh K., (2013). PRISM: PRIority based simulated annealing for a closed loop supply chain network design problem. Applied Soft Computing. Volume 13. Issue 2. P 1121-1135.

[36] Subramanian P., Ramkumar N., Narendran T.T., Ganesh K., (2014). A bi-objective network design model for multi period, multi-product closed-loop supply chain, Journal of Industrial and production Engineering. Volume 30. Issue 4. P 264-280.

[37] Sahebjamnia, N., Fathollahi-Fard, A. M., \& Hajiaghaei-Keshteli, M. (2018). Sustainable tire closed-loop supply chain network design: Hybrid metaheuristic algorithms for largescale networks. Journal of cleaner production, 196, 273-296.

[38] Teimoury, E., Nedaei, H., Ansari, S., \& Sabbaghi, M. (2013). A multi-objective analysis for import quota policy making in a perishable fruit and vegetable supply chain: A system dynamics approach. Computers and electronics in agriculture, 93, 37-45.

[39] Üster, H., Easwaran, G., Akçali, E., \& Çetinkaya, S. (2007). Benders decomposition with alternative multiple cuts for a multi- product closed- loop supply chain network design model. Naval Research Logistics (NRL), 54(8), 890-907.

[40] Vahdani, B., \& Mohammadi, M. (2015). A bi-objective interval-stochastic robust optimization model for designing closed loop supply chain network with multi-priority queuing system. International Journal of Production Economics, 170, 67-87.

[41] Wei, J., Govindan, K., Li, Y., \& Zhao, J. (2015). Pricing and collecting decisions in a closed-loop supply chain with symmetric and asymmetric information. Computers \& Operations Research, 54, 257-265. 